sound made by the leopard and, probably for the same reason, a certain musical instrument must not be played.

The owner of Togba medicine is obliged to wash her hands after she has touched cassava leaves, palm kernels, or palm kernel oil.

When a procession through the village is planned, the Togba women assemble at the Togba hut, where the leading members live. Here they are received by the head woman and three females of the higher grades; one of them has a whip in her hand, the second carries a copper basin filled with medicinal water which she sprinkles on the village road which the women are to follow, and the third carries a calabash containing a dark-blue liquid which she sprinkles on the women while they are walking in procession. The heels, chest, and forehead of the head woman's husband are also rubbed with this liquid. The women move about between the huts with short dancing steps. From time to time the head woman advances in front of the group and dances by herself. Since in this country women are not allowed to do or to use any wood-work, no drums are beaten to accompany the dance, but sawn-off cow horns are used instead; tortoise shells are also employed for the same purpose.

When night falls the procession ceases and the women disappear into their Togba house. The whole village is then filled with protective medicine and is safe against the inroads of wicked leopards. (Communicated by Fräulein ETTA DONNER, Vienna.)

\title{
The Energetic Philosophy of Primitive Man.
}

IN a study on 'Das energetische Weltbild der Primitiven' (Jahrbuch der österreichischen Leogesellschaft 1934) V. Lebzelter discusses the problem of the energetic philosophy of primitive man. With primitive and civilized peoples, two modes of thinking must be distinguished: reproductive and recapitulative thinking. Most men do not reproduce traditional conclusions, they only recapitulate them. This is almost always done by our informants among primitive peoples. Science has considered early and primitive man too much as a philosopher and too little as a scientist. The animist, like our scientist, possesses names for that which, as cause of the real or supposed qualities of matter, remains unknown. It is well known that in the history of philosophy the problem whether empirical things are realities, or whether they only become realities in our imagination, comes to the fore again and again. Primitive man has answered this question from the beginning in the positive in both directions, but, on the other hand, his philosophy altogether lacks the conception of inert matter. He takes existence for granted; not stationary objects but things, happenings, rouse his attention. He conceives the objects of both his own mind and the external world only in the state of expending energy. He sees the world as an interplay of forces only. Within a magnetic or electrical field, for example, or a field of gravity, 
as we conceive it, the state of all the particles contained is changed by the influence of an energetic medium. At the same time, we understand these effects as produced from outside. Now the world of primitive man consists of a great number of overlapping fields of energy. For the energies at work in them which are by no means always considered as personal, the native naturally has definite names that we, in most cases unjustly, take to be names of spirits. It is suggested therefore, that essentially primitive man has no 'magic' at all, for, originally, the natives understand by using ' magic' not the exploitation of occult or supernatural forces of some kind, but the domination of nature by means of their own resources. Actions, however, that are based on the reproduction of logical conclusions cannot be considered as magic. 'Magic' in the disparaging sense of the word might be deemed to refer only to such acts as are conditioned by thoughtless recapitulation, mostly by analogies. But this is also the case when a European turns on an electric contact without knowing why the intended effect takes place.

\section{An Anthropological Expedition to Tanganyika.}

THE aim of this expedition was to study anthropological and linguistic conditions in the interior of Northern Tanganyika, between Lake Eyassi and Dodoma, particularly among the people of small growth. Field work was started in August 1934, among the Tindiga, a people of definite pygmy characteristics, though they have certainly intermarried with neighbouring groups belonging to other races. The average height of the males is $1.58 \mathrm{~m}$., and that of females $\mathrm{I} \cdot 45 \mathrm{~m}$. A bright colouring on the forehead, above the nose and on the cheeks, was often observed, which seems to show that the original 'pygmy stock' is present in the population. Later the expedition moved on to the Wahi people who, like the Tindiga, are primitive hunters; they live west of Lake Eyassi and speak the same language as the Tindiga. Other tribes reached and, at least in part, studied are the Isansu, Iramba, Sandawe, and Burungi. Of particular interest were the Ngomvia; they are cattleowners and agriculturists, living south-east of the Sandawe. Their language is related to that of the Burungi.

The expedition was also able to do archaeological work. In the Tindiga country two types of burial-places were discovered. Moreover caves were found in the Mumba hills, some of them with rock paintings. They were of various styles, some very primitive, but others more elaborate; all the pictures were monochrome, either red or white, a few being yellow or black. Some were drawn in outline, and in some the whole figure was coloured. In the Sandawe country rock engravings were found. Large numbers of artefacts were collected all over the area visited. Along the shores of Lake Eyassi a sandbank containing a rich diluvial fauna, and a human skull, were discovered. (Communicated by Dr. L. KoHL-LARSEN.) 